\title{
Microsilica-Cement Stabilization of Organic Contaminated Soil: Leaching Behaviour of Polycyclic Aromatic Hydrocarbons
}

\author{
SOHEIL AHMADI*, SAEID GITIPOUR, SAMANEH MARZANI and NASSER MEHRDADI
}

Department of Environmental Engineering, Faculty of Environment, University of Tehran, Tehran, Iran.

http://dx.doi.org/10.12944/CWE.11.1.03

(Received: February 02, 2016; Accepted: February 17, 2016)

\begin{abstract}
In this study, Polycyclic Aromatic hydrocarbons (PAHs) contaminated soil were collected from Ray Petrochemical industry and treated by Solidification/Stabilization (S/S) which is an effective technique for reducing the leachability of contaminants in soils. Since organic compounds interfere with cement hydration process, S/S technology will have difficulties while trying to immobilize organic contaminants. The treatment process was conducted using Portland Cement (PC) as the main binder and Microsilica (MS) as an additive to improve the effect of PC in immobilization of organic contaminants. Specimens were divided in two groups with constant cement percentage of $25 \%$ and $35 \%$. Each group were again divided to three subgroups with $0 \%, 4 \%$ and $8 \%$ of MS. The efficiency of using MS in leaching behaviour of $\mathrm{S} / \mathrm{S}$ samples was assessed by toxicity characteristic leaching procedure (TCLP). Lowest leach percentage of $14.66 \%$ for total PAHs in the paste contained $25 \%$ of cement and $8 \%$ of MS were obtained. The results indicated that the presence of MS in cement pastes had positive effect on reduction in concentration of contaminant in leachate.
\end{abstract}

Key words: Sotabilisation, Solidification, TCLP, Microsilica, PAHs, Portland Cement.

\section{INTRUDUCTION}

Soil pollution is an ordinary side-effect of several industries. The oil industries is mainly responsible for soil contamination due to actions related to crude oil extraction, refineries and transfer, underground crude oil storage tanks and the wastewaters ${ }^{1}$.

Polycyclic aromatic hydrocarbons (PAHs) are one of such above mentioned contaminants. They are hydrocarbons-organic compounds containing only carbon and hydrogen, consist of two or more benzene rings ${ }^{2}$. United States Environmental Protection Agency (USEPA) named 16 different compounds of PAHs as priority pollutants according to their carcinogenicity and mutagenicity at very low concentrations $\mathbf{s}^{3,4}$.
Stabilization/Solidification (S/S) method has been widely used for treatment of heavy metals ${ }^{5}$ and other contaminants in hazardous wastes, industrial sludges, power plant residues, municipal ashes, nuclear wastes, and contaminated soils and debris before final disposal since 20 years $\mathrm{ago}^{5}$. USEPA documented S/S method as the Best Demonstrated Available Technology (BDAT) for the land disposal of the majority toxic and hazardous substance ${ }^{6-8}$. Furthermore, it is one of the most regular remediation processes used at Superfund sites in the U.S. (about $24 \%$ of the sites applied this method between 1982 and 2002) $)^{8,9}$, and it has been known as one of the most cost effective techniques ${ }^{10,11}$. The stabilization stands for a process that is convert contaminants into forms that are much less mobile, soluble, and toxic $^{8,11}$. Additionally, solidification encapsulated 
the contaminants within a monolithic solid with high structural integrity ${ }^{8,11}$.

Since organic compounds interfere with cement hydration process, S/S technology could be run into difficulties when trying to immobilize organic contaminants $^{12,13}$. A possible process for improving the efficiency of S/S for organic contaminants is using binders as an additive like fly ash, modified clay, activated carbon ${ }^{14}$. Microsilica (MS) is a byproduct of the smelting process of silicon metal and ferrosilicon alloy production ${ }^{15}$. It's amorphous structure, high $\mathrm{SiO}_{2}$ content, and large surface area makes it reactive with calcium hydroxide produced by cement hydration ${ }^{15-17}$.

The aim of this research was to analyse the effect of adding MS on leaching behaviour of high oily PAHs contaminated soil solidified and stabilized by Portland cement.

\section{MATERIALS AND METHODS}

\section{Sampling and preparation}

Soil sampling was carried out from different parts of petrochemical industry (Rey Petrochemical Industry) located in the South-East of Tehran, Iran (Figure 1).

Following collection of the samples, they were dried at room temperature for 24 hours. Subsequently soil samples moved into $1000 \mathrm{ml}$ glass jars and then placed in fridge (with the temperature of $\left.4{ }^{\circ} \mathrm{C}\right)$. American Society for Testing and Materials (ASTM) methods were performed to characterize the properties of soil samples ${ }^{18}$ (Table 1$)$.

\section{Binders}

$P C$ is most frequently used and widely studied binder. S/S with cement is widely understood and simple, is easily available and results in a stable product ${ }^{19}$. The PC applied in this study was obtained from Tehran Cement Factory. Other binders (activated carbon, fly ash, MS, modified clay, lime, etc.) can be partially added to PC, which can enhance or negatively affect the properties of cement in $\mathrm{S} / \mathrm{S}^{19-21}$.

The properties of MS are determined by the procedures it has been undergone during the manufacturing, also based on this its colour could vary from light to dark gray. The surface area of MS varies between 15,000 to $35,000 \mathrm{~m}^{2} / \mathrm{kg}$ and its average diameter is smaller than 1 ìm and it can come in different forms of slurry, powder and condensed ${ }^{22,}$ ${ }^{23}$. Numerous researchers have been conducted during past years to evaluate the properties of concrete by adding MS to the cement ${ }^{24-26}$. Table 2 contains the Comparative Physical properties and chemical compositions of MS and PC which have been used in this study.

Its effects are related to the strength, ductility, air void content, freeze-thaw durability, permeability, shrinkage, creep rate, specific heat, abrasion resistance, coefficient of thermal expansion

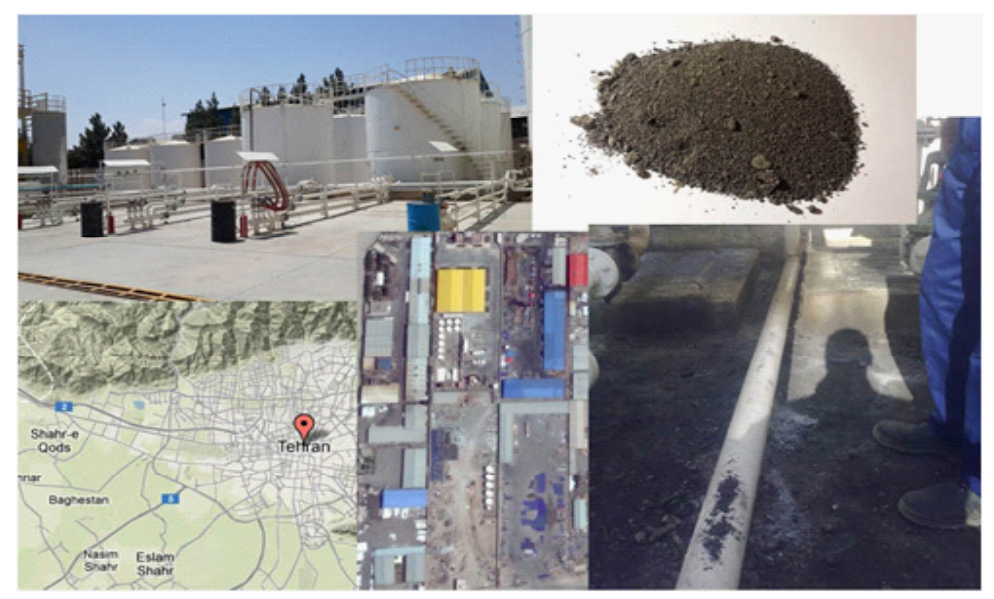

Fig. 1: PAHs contaminated soil sample collected from Rey Petrochemical Industry 
(CTE), chemical attack resistance, bonding strength with reinforcing steel, defect dynamics, thermal conductivity, and degree of fibre dispersion in mixes containing short microfibers ${ }^{26-29}$.

\section{Preparation of specimens}

The various mixes and their designations in presence, absence and different ratios of MS used in this study are shown in Table 3. Specimens were divided in two groups:

- $\quad$ C25 with constant Portland cement percent of 25

- $\quad$ C35 with constant Portland cement percent of 35

Samples were transferred into the molds which have been made due to ASTM D 1633:00 method $A$ with the Height to diameter ratio equals $1.15^{18}$.

\section{Testing method}

The United States Environmental Protection Agency (USEPA) developed toxicity characteristic leaching procedure (TCLP) to simulate the worst possible situation for disposal of municipal solid waste and hazardous waste in a landfill and has been widely applied as a regulatory test to evaluate contamination levels ${ }^{30,31}$. During last decade, the TCLP has been used extensively to test the leachability of contaminations in soils to evaluate the efficiency of contaminant immobilization ${ }^{32,33}$.

For conducting leaching of the crushed wastes, Method 1311 of SW-846 of the USEPA (1992) Toxicity Characteristics Leaching Procedure was used ${ }^{34,35}$. Cylinders samples were crushed to less than $9.5 \mathrm{~mm}$ in size After 28 days of curing. Acetic acid-water solution with the $\mathrm{pH}$ of 2.88 was used as a extraction fluid and the liquid-to-solid ratio of it was 20:1. it was added to the crushed specimens at room temperature and were rolled thoroughly for $18 \mathrm{hr}$ in extraction bottles made of stainless-steel at 28 to $30 \mathrm{rpm}$. A $0.45 \mathrm{im}$ membrane filter was used to remove suspended solid from the leachate and finally gas chromatograph with flame-ionization detector (GC-FID) and split/splitless injector were used to analyse the $\mathrm{PAHs}^{35}$.

Table 2: Compared chemical

Table 1: Characteristics of soil samples in Ray Petrochemical Industry

\begin{tabular}{lc}
\hline Soil Properties & Value \\
\hline Gravel & $4.30 \%$ \\
Sand & $69.50 \%$ \\
Silt \& Clay & $26.20 \%$ \\
Moisture Content & $38 \%$ \\
pH & 6.21 \\
\hline
\end{tabular}

\begin{tabular}{lcc}
\hline Compound & PC(\%) & MS(\%) \\
\hline $\mathrm{SiO}_{2}$ & 22.57 & 87.6 \\
$\mathrm{Al}_{2} \mathrm{O}_{3}$ & 5.31 & 1.35 \\
$\mathrm{Fe}_{2} \mathrm{O}_{3}$ & 3.25 & 0.9 \\
$\mathrm{SO}_{3}$ & 0.59 & 0.13 \\
Specific Surface & 312 & 23500 \\
$\left(m^{2} / \mathrm{Kg}\right)$ & & \\
\hline
\end{tabular}
compositions and physical properties of PC and MS

Table 3: Mixing Ratio

\begin{tabular}{lcccc}
\hline $\begin{array}{l}\text { Mixing } \\
\text { code }\end{array}$ & PC/ Soil & $\begin{array}{c}\text { MS/ Contaminates } \\
\text { Soil }\end{array}$ & $\begin{array}{c}\text { Contaminated } \\
\text { Soil (gr) }\end{array}$ & W/C \\
\hline $\mathrm{C}_{25} \mathrm{MS}_{0}$ & 0.25 & 0 & 55 & 0.35 \\
$\mathrm{C}_{25} \mathrm{MS}_{4}$ & 0.25 & 0.04 & 55 & 0.35 \\
$\mathrm{C}_{25} \mathrm{MS}_{8}$ & 0.25 & 0.08 & 55 & 0.35 \\
$\mathrm{C}_{35} \mathrm{MS}_{0}$ & 0.35 & 0 & 55 & 0.35 \\
$\mathrm{C}_{35} \mathrm{MS}_{4}$ & 0.35 & 0.04 & 55 & 0.35 \\
$\mathrm{C}_{35} \mathrm{MS}_{8}$ & 0.35 & 0.08 & 55 & 0.35 \\
\hline
\end{tabular}




\section{RESULTS AD DISCUSSION}

\section{Leaching Behaviour}

PAHs Concentrations in TCLP leachate were evaluated by GC apparatus. For analyzing the efficiency MS in S/S process, a control sample of contaminated soil without any added MS was used, and the contaminants' concentrations in leachates of solidified samples were compared to that of control samples as an index (100\%). Wherever this amount is closer to zero indicates the higher solidification and stabilization prohibiting performance. Two factors of the $\mathrm{S} / \mathrm{S}$ process effectiveness were investigated: (1) concentration of contaminants; and (2) effect of using MS in leachate behaviour. Table 4 and Table 5 show the results of leachate concentrations and percentages. These observations indicated that addition of MS played a significant role in decreasing the amount of leachate in $\mathrm{S} / \mathrm{S}$ specimens compared to the untreated contaminated soil.

In group C25 with 4 percent MS (C25MS4), $\mathrm{B}[\mathrm{a}] \mathrm{P}$ with $22.47 \%$ was the specimen with the least leachate percentage. Whilst, in C25 specimens with the $8 \% \mathrm{MS}$, the least leaching percent belonged to $\mathrm{B}[\mathrm{a}] \mathrm{A}$ with amount of $6.06 \%$. results showed that with increasing the MS content to $8 \%$ a reduction of almost $50 \%$ in average leachate percentage would be observed. Confirming the above mentioned results the 36.54 percent TPAH leachate in C25MS4 decreased to 14.66 in C25MS8.

Data from group C35 showed differences to of group C25. Although 4 percent content of MS resulted in decrease in amount of leaching, with increasing MS to 8 percent not only no improvements were observed but also there was a noticeable increase in leaching percent. This occurrence probably caused due to the fact that using MS increases the water demand of samples for hydration and using more MS defected the cement hydration process in samples ${ }^{24,36}$.

The relation between the contaminant's release and the MS proportion was found to have a logarithmic pattern, which is shown for different

Table 4: Relative concentration of PAHs leaching in S/S samples

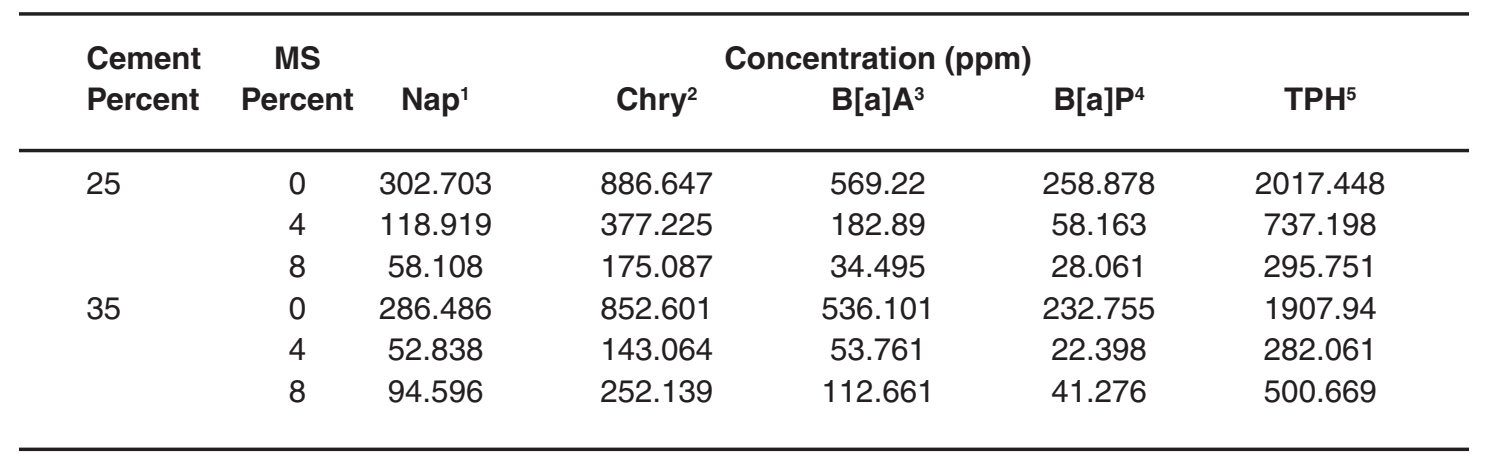

1. Naphtaline, 2. Chrysene, 3. Benzo[a]Anthracene, 4. Benzo[a]Pyrene,5. Total Polyaromatic Hydrocarbon

Table 5: Relative Leaching percentage of PAHs

\begin{tabular}{lcccccc}
\hline $\begin{array}{l}\text { Cement } \\
\text { Percent }\end{array}$ & $\begin{array}{c}\text { Micro } \\
\text { silica Percent }\end{array}$ & NAP & Cry & B[a]A & B[a]P & TPH \\
\hline \multirow{2}{*}{25} & 0 & 100 & 100 & 100 & 100 & 100 \\
& 4 & 39.29 & 42.55 & 32.13 & 22.47 & 36.54 \\
& 8 & 19.2 & 19.75 & 6.06 & 10.84 & 14.66 \\
35 & 0 & 100 & 100 & 100 & 100 & 100 \\
& 4 & 21.93 & 16.78 & 10.03 & 9.62 & 14.78 \\
& 8 & 33.02 & 29.57 & 21.01 & 17.73 & 26.24 \\
\hline
\end{tabular}


cement mixes in Figures 2 and 3. High correlation coefficients $(r 2>0.94)$ indicate that a slight increase of the Micro Silica significantly reduces the concentration contaminants in leaching.

In addition, equations extracted from Figure 2and 3illustrated that increasing in cement percent in S/S samples enhanced the efficiency of removal. However, Ln coefficients in the equations demonstrated that this improvement could be considered insignificant compared to the effect of MS in leaching behaviour of solidified and stabilized samples.

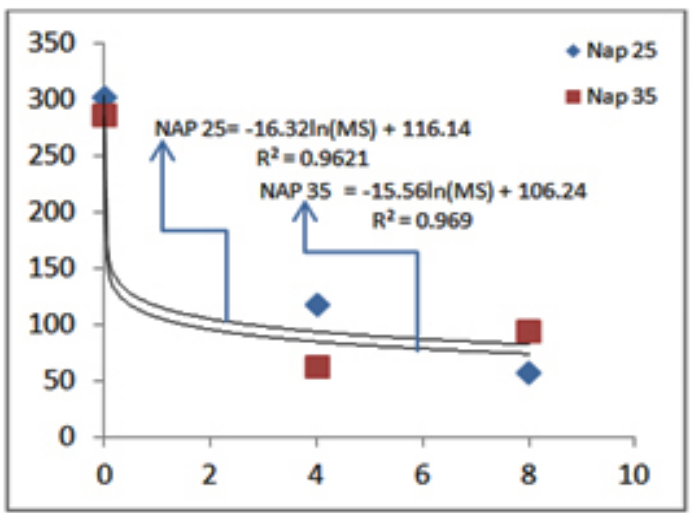

Fig. 2: logarithmic relationship between leachate and percent of Micro Silica for Naphtalin and chrysen
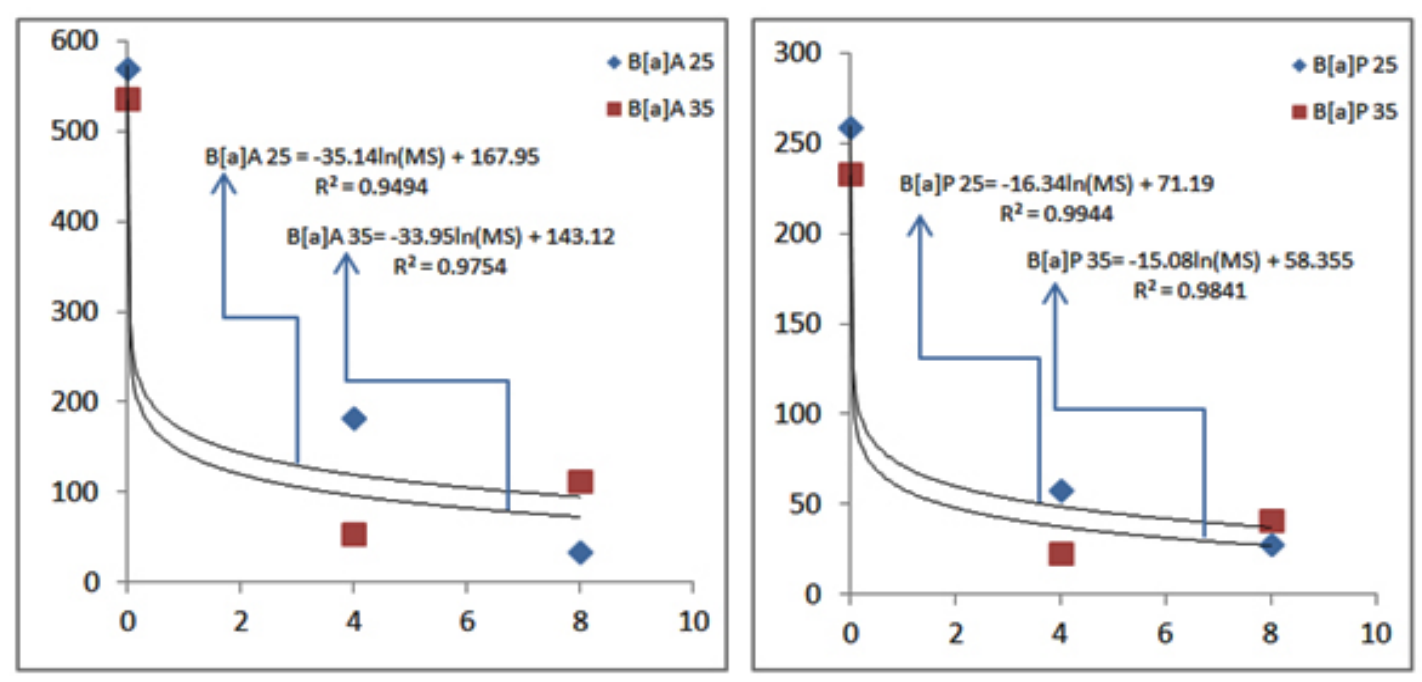

Fig. 3: relationship between leachate and percent of Micro Silica for Benzo[a]Anthracene and Benzo[a]Pyrene 
toxic one. Conclusions of this study are highlighted below:

- The least contaminated leachate was related to $\mathrm{B}$ [a]A paste S/S by $25 \%$ cement and $8 \%$ of MS with the $6.06 \%$

- In group C 25 increasing in MS percentage from $4 \%$ to $8 \%$ resulted in almost $50 \%$ reduction in contaminant leachability of contaminated soil.

- $\quad$ The TPAH leachate of the specimens S/S by $25 \%$ cement and $8 \%$ MS were lower than all of other S/S combinations

In group C35 adding more MS posed adverse effect on leachability of contaminants in S/S samples

- $\quad$ Analysis of diagrams extracted from leaching data illustrated that soil S/S by $35 \%$ cement and different portions of MS had better results in immobilization of PAHs

Equations extracted from results suggested that adding MS had more influence in S/S of the contaminated soil compared to the cement itself.

\section{REFERENCES}

1. Zamani, M.M., Fallahpour, M., Yousefi Harvani, G., Khodi Aghmiuni, S., Zamani, M., Minai Tehrani, D., Recent Proportionate Treatment Methods for Crude Oil Contamination Evaluation of the Tehran Refinery Site Soil. Thrita, 3(1): 12113 (2014)

2. Gitipour, S., M. Mohebi, and E. Taheri, Evaluation of Carcinogenic Risk Due to Accidental Ingestion of PAHs in Contaminated Soils. CLEAN - Soil, Air, Water, 39(9): 820826 (2011)

3. Essumang, D.K., D.K. Dodoo, and G. Hadzi, Distribution, levels, and risk assessment of polycyclic aromatic hydrocarbons in the soot of some kitchens in the Cape Coast Metropolis of Ghana. Toxicological \& Environmental Chemistry, 92(9): 1633-1647 (2010).

4. Gitipour, S., Firouzbakht, Saeid, Mirzaee, Ehsan, Alimohammadi, Masoumeh, Assessment of soil screening levels due to ingestion and dermal absorption of chrysene and benzo[k]fluoranthene and appropriate remediation method for Dorson Abad. Environmental Monitoring and Assessment, 186(6): 3541-3552 (2014.).

5. Gong, P. and P.L. Bishop, Evaluation of organics leaching from solidified/stabilized hazardous wastes using a powder reactivated carbon additive. Environmental Technology, 24(4): 445-455 (2003).

6. Shi, C. and R. Spence, Designing of CementBased Formula for Solidification/Stabilization of Hazardous, Radioactive, and Mixed Wastes.
Critical Reviews in Environmental Science and Technology, 34(4): 391-417(2004).

7. Singh, T.S. and K.K. Pant, Solidification/ stabilization of arsenic containing solid wastes using portland cement, fly ash and polymeric materials. Journal of Hazardous Materials, 131(1-3): 29-36 (2006).

8. Yoon, I.-H., et al., Mechanism for the stabilization/solidification of arseniccontaminated soils with Portland cement and cement kiln dust. Journal of Environmental Management, 91(11): 2322-2328 (2010).

9. (USEPA), U.S.E.P.A., Treatment Technologies for Site Cleanup: Annual Status Report, Twelfth Edition. 92 (2007).

10. Dermatas, D., Moon, D. H., Menounou, N., Meng, X., Hires, R., An evaluation of arsenic release from monolithic solids using a modified semi-dynamic leaching test. Journal of Hazardous Materials, 116(1-2): 25-38 (2004).

11. Conner, J.R., Chemical Fixation and Solidification of Hazardous Wastes. Van Nostrand Reinhold (1990)

12. Vipulanandan, C., Effect of clays and cement on the solidification/stabilization of phenolcontaminated soils. Waste Management, 15(5-6): 399-406 (1995).

13. Faschan, A., Tittlebaum, M., Cartledge, F., Eaton, $\mathrm{H}$., Effects of additives on solidification of API separator sludge. Environment Monitoring Assess, 18(2): 145-61 (1991).

14. Leonard, S.A. and J.A. Stegemann, Stabilization/solidification of petroleum 
drill cuttings: Leaching studies. Journal of Hazardous Materials, 174(1-3): 484491(2010).

15. Jun, K.S., H.S. Shin, and B.C. Paik, Microstructural analysis of OPC/silica fume/ $\mathrm{Na}$ bentonite interactions in cement based solidification of organic contaminated hazardous waste. Journal of Environmental Science and Health . Part A: Environmental Science and Engineering and Toxicology, 32(4): 913-928 (1997).

16. Mark Atkins, D.E.M. and P.G. Frederik, Chemical Modelling in Blended Cement Systems. Special Publication, 114 (1989).

17. Mehta, P.K., Pozzolanic and Cementitious byProducts in Concrete-Another Look. Special Publication, 114 (1989).

18. ASTM, Standard Test Method for ParticleSize Analysis of Soils, in ASTM International. (2007).

19. Malviya, R. and R. Chaudhary, Factors affecting hazardous waste solidification/ stabilization: A review. Journal of Hazardous Materials,. 17(1): 267-276 (2006).

20. Cheilas, A., Katsioti, M., Georgiades, A., Malliou, O., Teas, C., Haniotakis, E., Impact of hardening conditions on to stabilized/solidified products of cement-sewage sludge-jarosite/ alunite. Cement and Concrete Composites, 29(4): 263-269 (2007).

21. Garces, P., Perez Carrion, M., Garcia-Alcocel, E., Paya, J., Monzo, J., Borrachero, M. V., Mechanical and physical properties of cement blended with sewage sludge ash. Waste Manag, 28(12): 2495-502 (2008).

22. Panjehpour, M., A.A. Abang Ali, R. Demirboga, A review for characterization of silica fume and its effects on concrete properties. International Journal of Sustainable Construction Engineering and Technology, 2(2) (2011).

23. Wang, X., Pan, Z., Zhu, C., Zhu, H. Reaction degree of silica fume and its effect on compressive strength of cement-silica fume blends. Journal of Wuhan University of Technology-Mater. Sci. Ed., 29(4): 721-725 (2014).

24. Malhotra, V.M., Condensed silica fume in concrete.CRC Press (1987).

25. Della, M.R., Fly Ash and Silica Fume
Chemistry and Hydration. Special Publication, 114 (1989).

26. Behnood, A., Ziari,H. Effects of silica fume addition and water to cement ratio on the properties of high-strength concrete after exposure to high temperatures. Cement and Concrete Composites, 30(2): 106-112 (2008).

27. Chung, Deborah D.L.Tailoring Composite Materials, in Composite Materials: Science and Applications. Springer London: 157-201 (2010).

28. Mazloom, M. Estimating long-term creep and shrinkage of high-strength concrete. Cement and Concrete Composites, 30(4): 316-326 (2008).

29. Mazloom, M., Ramezanianpour, A.A., Brooks, J.J. Effect of silica fume on mechanical properties of high-strength concrete. Cement and Concrete Composites, 26(4): 347-357 (2004).

30. Mantis, I., D. Voutsa, and C. Samara. Assessment of the environmental hazard from municipal and industrial wastewater treatment sludge by employing chemical and biological methods. Ecotoxicology and Environmental Safety, 62(3): 397-407 (2005).

31. Dermatas, D., Chrysochoou, M., and Moon, D. Geoenvironmental Characterization to Assess Waste Stabilization/Solidification Treatment Performance and Sustainability. in GeoCongress 2008: 660-667 (2008).

32. Scheckel, K.G., Diamond, G.L., Burgess, M.F., Klotzbach, J.M., Maddaloni, M., Milller, B.W., Partridge, C.R., Serda, S.M. Amending soils with phosphate as means to mitigate soil lead hazard: a critical review of the state of the science. J Toxicol Environ Health B Crit Rev,. 16(6): 337-80 (2013).

33. Tsang, D.C.W., Olds, W.E., Weber, P.A., Yip, A.C.K. Soil stabilisation using AMD sludge, compost and lignite: TCLP leachability and continuous acid leaching. Chemosphere, 93(11): 2839-2847 (2013).

34. Tiwari, M.K., Bajpai, S., Dewangan, U. K., Tamrakar, R. K. Suitability of leaching test methods for fly ash and slag: A review. Journal of Radiation Research and Applied Sciences, 8(4): 523-537 (2015).

35. Patel, H. and S. Pandey. Evaluation of 
physical stability and leachability of Portland Pozzolona Cement (PPC) solidified chemical sludge generated from textile wastewater treatment plants. Journal of Hazardous Materials,. 207-208: 56-64 (2012).
36. Köksal, F., Altun, F., Yiðit, I., Pahin, Y. Combined effect of silica fume and steel fiber on the mechanical properties of high strength concretes. Construction and Building Materials, 22(8): 1874-1880 (2008). 